\title{
A Study on Cross-border M\&A of China State-owned Energy Enterprises Based on SWOT analysis
}

\author{
Feng Yini ${ }^{1}$, Meng Qingjun ${ }^{2}$ \\ Business School,Hohai University,Nanjing,P.R.China,211100 \\ fiona-yn.feng@hotmail.com
}

\begin{abstract}
Cross-border mergers and acquisitions are the necessary prerequisites to expansions overseas of China state-owned energy enterprises. By using modern enterprise strategic tool "SWOT analysis", this paper has an in-depth analysis of the cross-border M\&A of China state-owned energy enterprises, which contains internal conditions (strengths and weaknesses) and external environment (opportunities and threats) factors, and builds a SWOT analysis matrix model for cross-border M\&A of China state-owned energy enterprises. It shows that China state-owned energy enterprises should increase both the capital inflows and the technology exports, cultivate international talents, introduce innovative skills, improve the cross-border M\&A management system and establish cross-border information service network.
\end{abstract}

Keywords: SWOT Analysis, State-owned Energy Enterprises, Cross-border Mergers and Acquisitions, China

\section{Introduction}

Cross-border M\&A plays an important role in integrating social resources. China is a developing country with large demand for energy and resources. China is a populous country with a low share of energy resources per capita. In order to get rid of the shortage of domestic energy supply, and to avoid the risk of international energy resource price hiking, China's state-owned energy enterprises (hereinafter referred to as the "State-Owned Energy Enterprises") can only break through the constraints of low share of domestic energy resources per capita, further safeguard the energy support of the sustainable development of China's economy, and enhance the voice in the global energy market, through large-scale overseas M\&A. In recent years, China's energy transnational development has shown a trend of double increase in both the number of cases and the amount of investment, and, as the participant with absolute advantages, the State-Owned Energy Enterprises have contributed greatly to the security of domestic energy supply.Based on "SWOT analysis", which is a extensively used tool of analysis in the strategic management and planning, this paper explores the way to promote the coordinated development of Cross-border M\&A structure with the advantage and the opportunity of state-owned energy enterprises, and hence realize a sustainable economic and social development of Cross-border M\&A.

\section{The Internal Conditions of Cross-border M\&A of the State-Owned Energy Enterprises}

\subsection{Strengths}

1). Sufficient Funds

State-Owned Energy Enterprises have a dominant position in China's energy industry. They have large assets and income, and are in good financial conditions. They have a high credit line in domestic banks, and have built strong financial management and capital operation platforms in Hong Kong and other places. By making full use of both domestic and foreign capital markets, they are expanding the low-cost financing channels, in order to secure the funding for cross-border energy M\&A. The current global economy is actually dominated by international financial capital. The State-Owned Energy Enterprises dock their own capital operation platform with international financial capital market, which will help accelerate the realization of internationalization.

2). Mature Technology[1]

State-Owned Energy Enterprises have advantages on proprietary technology, and some technologies even occupy monopoly positions in the international market. The credit of the best contribution on 
China's energy technology innovation must go to the State-Owned Energy Enterprises. In recent years, China's energy science and technology innovation capacity as well as the technical equipment independence level have been greatly enhanced, a number of international advanced demonstration projects on important energy technology have been set up, and the key technologies on the exploration of shale gas, dense oil and others as well as the key technology of UHV transmission have been mastered. Advanced technologies lay a solid foundation for technical output in overseas M\&A.

\subsection{Weaknesses}

1). Weak International Management Structure[2]

The State-Owned Energy Enterprises still lack effective measures on internal control and risk management of the overseas business. The corresponding organizational structure and management system reflecting the headquarters' integrated management and control system have not been fully put into place. Especially in the life cycle of an overseas project, there is no mature international management and operation mechanism, or independent and complete international brand management system, between and among the headquarters and the secondary subsidiaries, the secondary subsidiaries and professional subsidiaries, the domestic controlling companies and the overseas investment subsidiaries. Moreover, a State-Owned Energy Enterprise often has a wide distributed industrial chain and a lot of management levels, which may cause duplicated capital allocation and excessive management range. With the continuous development of overseas business, it may lead to the separation of domestic and foreign business, and adverse to the internal resources integration.

2). Shortage of International Business Talent[3]

The rapid expansion of the overseas market business raised new demands and challenges to human resources of the State-Owned Energy Enterprises. At present, most of the staff have not yet mastered the specific processes, methods and skills to carry out the international business, lacking the practical experiences. Due to historical reasons, talent enrollment and training mechanism of the State-Owned Energy Enterprises are lagging behind, and the situation is aggravated by the seniority system. Thus the State-Owned Energy Enterprises are at a disadvantage in attracting high-quality international talent compared with the Western countries. The staff structure is not appropriate: staff dedicated to overseas projects often major in foreign languages, and only few of them are versatile with backgrounds of both technology and foreign language, which restricts the diversity of talent pool.

3). Low R\&D Capability[4]

Compared with the international well-known energy companies, the production technologies of State-Owned Energy Enterprises are relatively poor, the scientific and technological research and development capabilities are relatively weak, which can be seen in the following aspects: no clear working plan of technical innovation and scientific research; lack of investment in R\&D of innovative technology, which limit the scientific and technological innovation; mainly rely on the foreign technology introduction and foreign technology licensing, resulting high cost of access to new technologies; some of the technical challenges raise the industry access threshold, hindering the development of new business.

\section{The External Environment Conditions of Cross-border M\&A of State-Owned Energy Enterprises}

\subsection{Opportunities}

\section{1). Global Market Demand}

First, the financial crisis and the follow-up European debt crisis. Due to the US financial crisis and the follow-up European debt crisis, the energy enterprises in most of the areas of the world suffered from sharp depreciation on their assets. Some foreign energy companies failed to effectively alleviate the liquidity shortage, and began the selling of assets, leading to a further decline in global energy assets prices, and a reduction in the cost of cross-border energy sector M\&A, which provides an important opportunity for China's State-Owned Energy Enterprises who have ample capital. For example, some countries in Europe, the Americas, Asia, Africa have clearly express in the public media that they will 
seek external investors globally to sell the shares and control of their energy enterprises, and welcome the Chinese enterprises to invest. Chinese energy companies receive less resistance for cross-border M\&A, get the valuable opportunities to integrate abroad the energy resources investment, can better diversify China's huge foreign exchange, and maximize their corporate value.

Second, changes in the international energy market. Because of the "energy independence" resulting from the shale gas revolution in the United States, Canada has to find new markets, which significantly changed the international energy environment. In 2011, the Minister of Natural Resources of Canada said that, from the perspective of strategic cooperation on trade, Canada would like to further expand collaboration with Asia-Pacific countries, especially China, and find more diversified markets around the world.

2). The National Marco Policy [5]

First, the Chinese government is actively promoting China's energy diplomacy strategy. In recent years, China and a number of countries rich in energy resources have frequent high-level meetings, which is in line with China's energy resources expansion strategy. In 2015, the National Development and Reform Commission, the Ministry of Foreign Affairs, the Ministry of Commerce jointly issued "The Vision and Action to Promote the Construction of the Silk Road Economic Belt and the 21st Century Maritime Silk Road". The construction of "Belt and Road" promotes the investment and trade cooperation. It can build a good business environment in the region and countries, eliminate investment and trade barriers, expand areas of mutual investment, and actively promote clean and renewable energy cooperation in hydropower, nuclear power, wind power and solar energy, and form the industrial chain integrating upstream and downstream for energy operation and cooperation. This is a very good opportunity for the development of the State-Owned Energy Enterprises.

Second, the Chinese government gives strong policy and financial support to Chinese enterprises' overseas M\&A. "Decision on Reform of Investment System" and "Interim Measures for the Approval of Overseas Investment Projects" have been introduced, which launched reforms and new regulations on Chinese enterprises' overseas investment, serving as a strong driver of their overseas M\&A. "Guidelines on Risk Management of M\&A Loans for Commercial Banks" promulgated by the China Banking Regulatory Commission (CBRC) clarified that eligible enterprises can obtain M\&A loans from commercial banks. This initiative has set a precedent for China's leveraged financing system. "The Notice on the Policy of Granting Credit Support to Key Foreign Investment Projects Encouraged by the State" provided financial support to the acquisition and development of overseas resources. Meanwhile, in order to further support Chinese enterprises' "going out", cope with the international financial crisis and promote sustainable economic growth, the "Overseas Investment Management Method" has also been put into effect to give more convenience to overseas investment of Chinese enterprises.

\subsection{Threats}

1). Resistance from the Host Country

Cross-border M\&A-based FDI has a huge impact on the flow of capital among countries, and some may even affect the host country's industrial restructuring, development trends and other aspects. Therefore, governments of many host countries conduct management and intervention on cross-border M\&A activities to protect the national economic security. Once involved in defense, energy M\&A will face complicated and severe examination and approval process. At the same time, cultural differences between the host country and China, nationalist sentiment, the host country's economic and trade operation mode, and the public opinion environment of social media in the host country, are all inevitable obstacles.

2). Business Information Asymmetry in International Market[6]

As a special market activity, cross-border M\&A involves at least two countries, and companies need to consider the impact of the factors of two different environment, so the collection of relevant information is particularly important. However, because of the particularity of cross-border M\&A, such as country differences and regional differences, it is difficult to collect international market business information. The transmission of information at various levels and the lack of sources will lead to more uncontrollable information asymmetry, which will generated a lot of obstacles to the 
transnational M\&A activity of the State-Owned Energy Enterprises.

\section{The SWOT matrix analysis about Cross-border M\&A strategy of State-Owned Energy Enterprises}

Conducting the matrix analysis of cross-border M\&A of state-owned energy enterprises, it can be determined 4 kinds combination of the cross-border M\&A strategies. First, the growth strategy is based on the existing cross-border M\&A optimization and upgrading; second, the reverse strategy is to eliminate the uncertainties of influence on cross-border M\&A; third, the diversification strategy is to cultivate new growth of cross-border M\&A; forth, the defense strategy is the establishment of basis of cross-border M\&A.

Table 1 SWOT matrix analysis of cross-border M\&A strategy

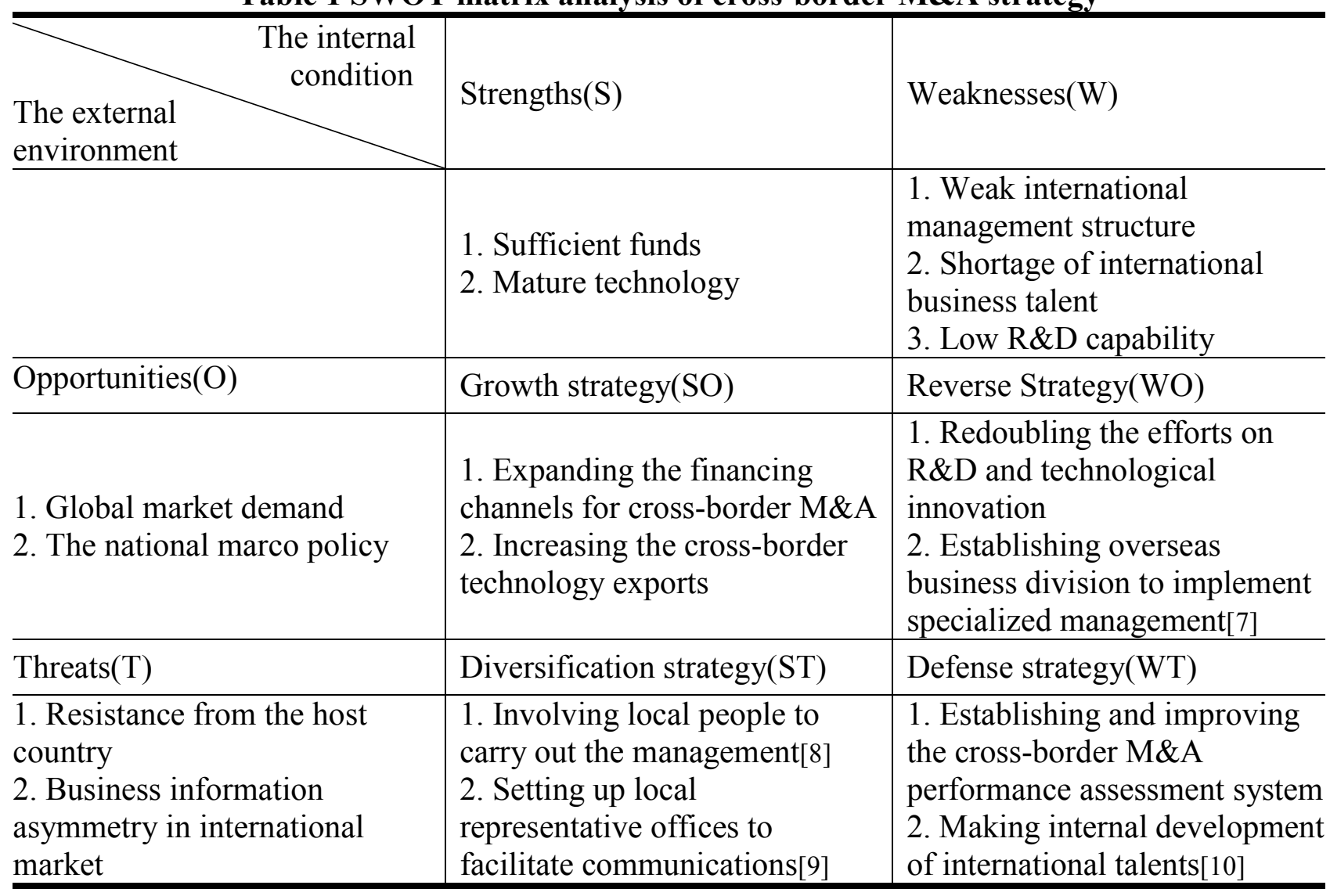

\section{Conclusions and Suggestions}

According to the SWOT matrix analysis, China state-owned energy enterprises should increase both the capital inflows and the technology exports, cultivate international talents, introduce innovative skills, improve the cross-border M\&A management system and establish cross-border information service network.

\subsection{To Increase Both the Capital Inflows and the Technology Exports}

Capital and technology are essential for the State-Owned Energy Enterprises to survive and develop. Cross-border M\&A needs huge amount of capital, something the State-Owned Energy Enterprises can get by using their sufficient funds to open up more effective cross-border M\&A financing channels to facilitate the cross-border M\&A. The State-Owned Energy Enterprises can utilize risk funds for overseas investments, which are funds led by the governments or professional financial institutions specially set up for supporting overseas investment activities of enterprises. Meanwhile, the State-Owned Energy Enterprises can also utilize the special cross-border M\&A financial instruments, which are instruments developed and led by China's policy banks taking full use of those banks' leading role of the market, and specially used for cross-border M\&A projects. Through the 
vigorous promotion of the commercial banks for the above instruments, the enterprises implementing cross-border M\&A can get inflow of funds more conveniently. Meanwhile, the State-Owned Energy Enterprises can also utilize direct financing from the international capital market. The State-Owned Energy Enterprises can expand their financing channels through issuing RMB bonds or foreign currency bonds abroad to provide financial support for cross-border M\&A. On the other hand, China's State-Owned Energy Enterprises have advanced technology that many developing countries want to abtain, and they can successfully develop cross-border M\&A by expanding their technology exports. In many developing countries, technologies are relatively backward, the infrastructures are in poor conditions, and the countries are heavily dependent on imports. With the world's leading technology, the State-Owned Energy Enterprises can take advantage of these opportunities to expand technology exports, so as to develop the cross-border M\&A successfully. The capital inflows and technology exports can facilitate the process of the cross-border M\&A of the State-Owned Energy Enterprises.

\subsection{To cultivate International Talents and Introduce Innovative Skills}

Talent is the core competitiveness of enterprise development. The State-Owned Energy Enterprises should carry out internal programs of talents cultivation. Through the selection, training and putting into practice of the existing staff, improving their comprehensive capability of the international business, they can establish talent polls with high-capacity, modernized, versatile talents. Internal talent cultivation is the basis of the establishment of an international talent team, relying on both internal human resources departments and external professional training institutions to carry out and provide staff with different types of tailored professional training with fruitful results. Meanwhile the introduction and cultivation of the external high level talents with overseas experiences and high proficiency, is the key for the rapid start-up of international business. The State-Owned Energy Enterprises can recruit local talents from enterprises or governments of the host countries and train them, so that those talents can make use of their familiarity of local culture, policies and information to gradually open the local market. Innovation is the inexhaustible diver for business development. The State-Owned Energy Enterprises should attach importance to the introduction and cultivation of high-tech and scientific research talents, so as to ensure their scientific research level and technological innovation ability, enhance their comprehensive competitiveness, and provide substantial support for future cross-border M\&A projects.

\subsection{To Improve the Cross-Border M\&A Management System, and Establish Cross-Border Information Service Network}

The establishment of a global network of information services can effectively mitigate the information asymmetry in the cross-border M\&A of the State-Owned Energy Enterprises. In the process of cross-border M\&A, when involving foreign-related policies and regulations, the State-Owned Energy Enterprises can actively promote the bilateral and multilateral trade mechanism negotiations among the relevant government departments of China and the host countries. Multinational enterprises should communicate in a timely manner with the target companies and the regulatory authorities of the relevant sectors of the host countries, carry out commercial diplomacy aimed at the host countries' governments, in order to create a more favorable competitive environment for the state-owned enterprises. The State-Owned Energy Enterprises should expand offices in the potential target markets, collaborate those offices with their existing offices, build cross-border information service networks, and engage professional organizations as consultants, in order to assure reliable and effective sources of information and to reduce the losses caused by the information asymmetry as much as possible in the process of cross-border M\&A. The State-Owned Energy Enterprises can also support their cross-border M\&A with mature diplomacy through the development of relationship with enterprises and governments in the host countries, utilizing the support from non-governmental organizations, chambers of commerce, politicians, etc. The establishment of a scientific and efficient modern enterprise system will enable the State-Owned Energy Enterprises to maintain a strong and lasting international competitiveness. The State-Owned Energy Enterprises should implement specialized management. In order to manage the overseas projects in a unified way, the State-Owned Energy Enterprises should set up overseas business 
divisions, which are responsible for the tracking, development and resource allocation of overseas projects. In order to meet the needs of their international development strategy, the State-Owned Energy Enterprises should continue to adjust their organizational structure, and implement specialized management. They should delegate HR management power and treasury power to specialized management departments, so that they can make independent operation and independent accounting, and gradually transform the managerial mode to that of the separated business divisions, and further implement the rights and responsibilities as required by the integrated control system. They should define the managerial responsibilities of the overseas business division, allow them to lead the coordination among the overseas project companies and the specialized management departments at the headquarters, and make it clear that the second-tier subsidiaries responsible for the overseas projects are under the unified management of the overseas business division. They should each establish a managerial and control system for the overseas project companies on aspects including the operation planning, performance appraisal as well as audit and supervision.

\section{References}

[1] Kong Xiangyang. The research on the development strategy of the large scale state owned energy enterprises [D]. University of International Business and Economics, 2015(in Chinese)

[2] Wan Jueying. The research of transnational merger and acquisition strategy of State Grid [D]. Beijing University of Technology, 2015(in Chinese)

[3] Xu Yanming. Internationalization strategy of PetroChina [D]. Wuhan University, 2012(in Chinese)

[4] Yang Haien. Foreign direct investment of Chinese petroleum enterprises [D]. Wuhan University, 2013(in Chinese)

[5] Wang Yuanhang. Research on the internationalization strategy of national Power Grid Corp [D]. Shanxi University, 2009(in Chinese)

[6] Li Shan. Study on the risks and Countermeasures of transnational merger and acquisition of state owned energy enterprises [D]. Southwestern University of Finance and Economics, 2014(in Chinese)

[7] Liwei Liu. The strategic selection of strategic emerging industry by Beijing energy investment holding based on SWOT analysis[A]. Information Engineering Research Institute, USA.Proceedings of 2014 International Conference on Environment and Sustainability(ICES 2014)[C].Information Engineering Research Institute, USA:,2015:7.

[8] WANG Baoqian. Research on the development strategy of the electric power industry financial holdings[A]. Faculty of Management and Economics, Dalian University of Technology. The fifth (2013) international symposium on financial risk and corporate finance[C].Faculty of Management and Economics, Dalian University of Technology:,2013:6.

[9] YE Lu. Status Quo and Problems of Chinese New Energy Industry and Suggestions for the Policy Making[A]. University of Electronic Science and Technology of China 、 Chinese Public Administration Society、American Society for Public Administration.2014 [C]. University of Electronic Science and Technology of China、Chinese Public Administration Society American Society for Public Administration:,2014:7.

[10] Shuangqin Liu. Study on the Outward FDI in the USA of Chinese Enterprises[A]. Scientific Research Publishing.Proceedings of the 9th International Conference on Management and Service Science (MASS 2015)[C].Scientific Research Publishing:,2015:5. 